\title{
Correction to: Performance evaluation of automatic object detection with post-processing schemes under enhanced measures in wide-area aerial imagery
}

Xin Gao ${ }^{1}$

Published online: 12 January 2021

(C) Springer Science+Business Media, LLC, part of Springer Nature 2021

Correction to: Multimedia Tools and Applications (2020) 79: 30357-30386 https://doi.org/10.1007/s11042-020-09201-0

In the original online version, there is an error on the title of Reference [48]. The author is regretful for this mistake. After peer-review and upon agreement, the correct version of [48] should be presented as below:

48. Philip RC, Ram S, Gao X, Rodríguez JJ A comparison of tracking algorithm performance for objects in wide area imagery. In: 2014 IEEE Southwest Symp. Image Anal. Inter-pret. (SSIAI), April 6-8, 2014, San Diego, CA, pp 109-112

Publisher's note Springer Nature remains neutral with regard to jurisdictional claims in published maps and institutional affiliations.

The online version of the original article can be found at https://doi.org/10.1007/s11042-020-09201-0

Xin Gao

xgao1985@email.arizona.edu

1 Department of Electrical and Computer Engineering, The University of Arizona, Tucson, AZ, USA 